A Plan for a Uniform Scientific Record of the Languages of Savages. Applied to the Languages of the Andamanese and Nicobarese. By Sir RICHARD C. Temple. Reprinted from the Indian Antiquary. Bombay: Bombay Education Society's Press, 1908.

The title of this work sufficiently explains its scope and contents : of the 106 pages which it amounts to in all, the first twenty-three are devoted to the exposition of the author's plan for a systematic universal scheme of grammar; the thirty-five following contain a grammar of Andamanese (with special reference to the speech of the Bea tribe); and the remaining forty-eight comprise a grammar of Nicobarese (with special reference to the Central dialect of that language), both on the lines of the projected plan.

It would require a very intimate acquaintance with these two languages (such an acquaintance as the author possesses, but very few other Europeans share) to give an adequate estimate of the success of the application of his principles. So far as a mere outsider can judge, his exposition gives a very clear view of two difficult forms of speech, one of which (the Andamanese) is most peculiar and singularly unlike anything that we are accustomed to. So far as this goes, it would seem that the scheme has proved capable of being applied to such cases. It must also be pointed out that it was applied in outline by Mr. Sidney Ray in the Indian Antiquary for 1902 to a short text in sixteen selected languages of various types, and in that instance also (so far as the experiment went) it met the requirements of the case.

It seems to me that this is the proper way of testing such a plan; solvitur ambulando is the only practical line to follow. Sir Richard Temple starts a priori with the principle that "as speech is a convention devised by the human brain for intercommunication between human 
beings, there must be some fundamental natural laws by which it is governed, however various the phenomena of those laws may be." But is speech a 'convention'? Is it not rather the outcome, to a great extent the unconscious and spontaneous outcome, of the mental nature of those who use it? And are we entitled to assume an identity of such nature throughout the human race? Unquestionably for any speech to develop and maintain itself there must be in the mind of the hearer much the same kind of way of looking at things (whether that be natural or acquired) as in the mind of the speaker, if there is to be a perfect understanding between the two. But speech has not been 'devised' (has not, I should prefer to say, developed) with an end to universal mutual intelligibility, but only for communication within a limited circle, originally probably in all cases very homogeneous from the psychological point of view. It seems to me that the principle from which the author starts is not quite a sure foundation for his system.

Everyone is agreed that writing the grammar of one language on lines derived from another is a fundamental mistake; it would be superfluous at this time of day to insist on the way in which the teaching of English grammar has been needlessly complicated and confused by following the principles of Latin. How much more has the grammar of uninflected, entirely alien languages been mangled by forcing them on to what some one has well styled the 'Procrustean bed' of Indo-European accidence and syntax. Any attempt to strike out a new and improved method of recording such fundamentally alien languages must be welcomed. The author, following a hint given by the late Mr. A. J. Ellis, has thought it necessary to devise a set of entirely new technical grammatical terms for the parts of speech; our old friends the noun, verb, etc., are replaced by such new ones as indicator, predicator, and so forth. This, it is to be 
feared, will prove a stumbling-block to many; nothing is so much a matter of habit as the use of an old-established terminology, and it cannot be denied that the introduction of a completely different one puts a considerable strain on the attention and memory of the reader; like the suggested new phonetic spelling, it worries him. On the other hand, there is the advantage claimed for it that it is free from the misleading associations of the old set of terms.

Certainly that is true, so far as matters of accidence are concerned; the word 'predicator' conveys to us no suggestion of conjugation, with its complexities of voice, mood, tense, and so forth. From these it is entirely abstracted, which is no doubt a great point gained, assuming that the word 'verb' was, in fact, by reason of early associations incapable of being freed from these ideas. But I am not sure that even this is the conclusion of the matter. What about syntax? Sir Richard Temple begins his analysis of speech with the sentence: rightly, as I conceive it, and, indeed, almost necessarily. A sentence, however, may, as he justly remarks, be composed of one word or more (in either case, to be a sentence it is necessary that it should be capable of conveying a complete meaning). It is when we come to analyse the sentence that the difficulties begin. For the very next step in the argument is that when a sentence consists of more than one word, it has two parts, the subject and the predicate, the matter to be discussed or communicated and the discussion or communication of it. On the face of it, this proposition seems incontrovertible. But are we not here already getting involved in our European (or Indo-European) system of logic, the product of our particular mental idiosyncrasy arrived at by the analysis of our own languages, which themselves are products of our mental characteristics? For it very soon becomes plain that the new term 'predicator' is but the old 
verb "writ large." But that assumes a system of syntax fundamentally, in its broad outlines at least, resembling ours, with the noun (or its substitutes) as subject, the verb (or its substitutes and amplifications) as predicate, and so on into the further subdivisions of the analysis.

Is this system, which is so familiar to us that we find it difficult to think at all outside the lines that it lays down, really of universal and exclusive validity? Is it not possible to conceive a language that should marshal its parts of speech (i.e. represent the mental relation of its ideas) in quite another way? Why should the verb necessarily fall into the predicative part of the sentence? Could it not just as well be the other way about? By this I do not mean anything analogous to the old IndoEuropean verb, in which the inflectional suffixes embody a pronominal subject; here it is open to anyone to make the analysis into subject (represented by the pronominal termination) and predicate (being what is left of the verb shortened of its pronominal termination). What I conceive as possible is the treatment of the verbal idea, the action, process, or (if one may so style it) the dynamic element of the sentence, as the subject, making the words that we should take as subject, object, etc., subordinate to it, while the real predicate (which in an affirmative sentence of this sort would be merely an affirmation that the action expressed by the verb-subject is an actuality) would either be represented by a particle of affirmation or be already implicitly involved in the form of the verb-subject itself.

To me such a syntactical system, strangely different as it is from the normal form of our own, seems quite conceivable, nay more, I believe it to exist sometimes as a fact. Take as an example the following Malay sentence (not made up by myself ad hoc, but extracted from Gerth van Wijk's "Spraakleer der Maleische Taal," 2nd ed., p. 96, and presumably derived from a genuine Malay prose-work): di-chium-nya dan di-tangis-nya oleh bonda-nya akan 
anak-nya itu (I spell it in our English quasi-Hunterian fashion, not in the Dutch spelling of the original). Now, of course, we can render this into English simply thus: "the mother kissed and wept over her child." No question here but that the mother is the subject of the sentence. But that is not the way in which the sentence presents itself to a Malay. The verbs di-chium and di-tangis are passive in form, and the mother is the agent. Why not, then, render it (into less idiomatic English) " the child was kissed and wept over by its mother"? The objection to this is that it does not grammatically represent the original any more than the first rendering did. Akan anak-nya itu cannot be the subject, grammatically, because akan is a preposition used to connect a verb with its object. If we want to analyse the sentence literally as it stands, we must construe it thus : di-chium, 'was kissed ' (impersonal, simply expressing the actuality of the fact that kissing occurred); nya, 'by her' (i.e. the mother); dan, 'and'; di-tangis, 'was wept' (impersonal, like the preceding verb); nya, 'by her' (i.e. the mother); oleh, 'by'; bonda, 'mother'; nya, 'of it' (i.e. of the child); akan, 'over' (literally 'to'); anak, 'child'; nya, 'of her' (i.e. of the mother); itu, 'that' (but it has not in this context much more force than our definite article 'the'). If one would render it into something like English as nearly as possible as it stands, it would be "there was kissing and weeping by its mother over that her child."

In this rendering we have been forced by the structure of our own language to analyse the passive impersonal verbs $d i$-chium and di-tangis into (1) the verbal nouns 'kissing' and 'weeping,' plus (2) a verb of affirmation, 'there was'; but then we see that in the original the kissing and weeping really embody the subject, both grammatical and psychological, of the sentence, and that both the subject (which is further qualified by the words expressing the relations to it of the mother and child 
respectively) and the predicate (the affirmation of the actual occurrence as a fact) are contained in the two verbs. I confess that I am unable to fit such a sentence into Sir Richard Temple's scheme without doing violence to its natural structure, and I suspect that similar difficulties may occur in the case of other languages, especially in such sentences as we are accustomed to call impersonal. No doubt all such expressions can, by the exercise of a certain amount of ingenuity, be twisted into any system of syntax; but does not this greatly resemble the old Procrustean treatment that we all want to have done with? I confess that this seems to me an almost inevitable consequence of any system of grammatical terminology arrived at a priori and aiming at universality of application.

What, then, can one do to get over the difficulty? Every language (or group of similar languages) has its own set of parts of speech, resembling to some extent no doubt but not exactly coinciding with those of other tongues, and uses them in its own way. The task of the student of any language is to discover what, in that particular language, the parts of speech are and how they are used. When he has collected his individual facts and tabulated them, then only can he draw up his final terminology for the parts of speech and his rules for their use, arriving at them inductively from observation of the individual phenomena of the particular language. Such, it appears to me, is the really scientific order of proceeding. But it stands to reason that while he is carrying on his investigations, the student must have some provisional general scheme in his mind of what he is looking for, and that seems to me to be where the utility of Sir Richard Temple's plan comes in. As a provisional formal system of verbal categories I conceive that it may be of great service in the nature of a general ground-plan; probably in the majority of cases it would be sufficient in itself, 
though in some instances it might need to be supplemented or modified to meet special requirements. It might be necessary in the case of some languages to give somewhat different definitions of his terms, or perhaps to add to them by subdividing some of them. But the general framework of the terminology might remain.

To what extent precisely the terminology as a whole will be conveniently applicable to any particular language, can (I think) only be ascertained by experiment. No doubt it is true, as Sir Richard Temple remarks, that accidence arises properly out of syntax. But this really means that the accidence of a language arises out of its own syntax, and it is conceivable that forcing a language into a syntactical scheme that is not really its own may result in singularly complicating the rules we shall have to draw up when we come to the delineation of its accidence. Would it, to take an example given by Sir Richard Temple, be an advantage (either from the theoretical and systematic, or the practical point of view) to class the Latin form domino as an illustrator (adverb)? One does not feel sure that it would conduce to easier comprehension; the relations between form and function are so. complex and irregular that it seems best to keep the two things as much as possible apart; but, at any rate, one must not allow the study of the one to put difficulties into the study of the other.

It is impossible, within the limited time and space available, to attempt to touch upon, let alone discuss, all the points which this highly suggestive scheme seems to raise. The reader should turn to it himself and study it with the attention it deserves and requires, for it is not by any means easy reading, as was inevitable from the nature of its subject, but it deals very thoroughly (if its initial postulates be granted) with the principles involved. There is in places a good deal of repetition, but every separate proposition deserves to be critically 
considered and practically tested. This, however, is really outside the competence of a mere reviewer, who must necessarily confine his remarks to a very limited number of salient points, whereas the work ought really to be exhaustively discussed by specialists from various points of view in articles of adequate length.

I cannot part from this work without saying a few words about the two languages which are discussed in it. Both are of very special interest. The Andamanese because it is the speech of one of the most primitive, perhaps really quite the most primitive, of the races of man. The Negritos, both in their physical and mental characteristics, in their social condition and in their beliefs, have a strong claim to represent primitive man more closely and correctly than any other surviving race. It so happens that most of the Negrito communities, even such as have preserved a relative (though not unmixed) purity of blood, in other parts of their old domain have lost their own languages and adopted those of alien, more civilised neighbours. This is the case in the Malay Peninsula, where the Sermangs speak a substantially Mon-Khmer language, and also in the Philippines, where they speak a Malayo-Polynesian one. In the Andaman Islands, on the other hand, they have preserved their own tongue, and a very curious one it is. Like most languages of 'simple savages,' it is anything but simple in its etymological structure. But the most characteristic and interesting thing about it is its intensely anthropomorphic point of view. The Andamanese refers everything (that is in anywise capable of such reference) to himself, and not merely to himself as an individual but to the several parts of the human body, divided into some half a dozen classes, under such leading ideas as 'head,' ' hand,' ' mouth,' ' eye,' etc., with which more or less closely connected ones are grouped. Each such group is represented by a prefix, which has to be prefixed for instance to 
adjectives when used either with reference to any such part of the body or to other things which are conceived, by some remote analogy obscure to our modes of thought, as being connected with one or other of the groups. The result is a kind of 'concord' far more elaborate than that which results from our Indo-European genders and numbers. But what makes it so peculiarly interesting is the glimpse that it affords into the point of view of the Andamanese: if primitive man shared it with them, it would seem that to him his body and its parts were the real centre of his 'kosmos'; a somewhat more than Ptolemaic attitude of mind, one might style it.

Nicobarese is the speech of a much more advanced race. Its chief importance lies in the fact that having (like Andamanese) developed on its own ground, relatively free from disturbing foreign influences, it is a very archaic representative of the family of languages from which it sprang, and ought to be made the starting-point for a comparative study of all the allied groups, particularly the Mon-Khmer and Munda groups, Khasi, and the Sakai and Sermang dialects of the Malay Peninsula. Some beginning has already been made in this comparative study by Professor W. Schmidt, and it is to be regretted that Sir Richard Temple has not availed himself of it to revise the Table of Comparative Roots and Words (of Nicobarese, the Malay Peninsula dialects, and MonKhmer) on pp. 95-7 of his work. This is based on tentative comparisons made by myself a good many years ago, and though some of them have turned out to be right, others have been upset by newer data, and the list is by no means up to date. Subsequent investigations have added considerably to the number of words that are known to be common to these different languages. Nicobarese has, however, some points apparently peculiar to itself and not found in the allied languages. One of its marked characteristics is an extensive use of suffixes to 
differentiate roots and stems with reference to differences of direction, such as northwards, downwards, inwards, towards self, towards the landing-place, and so forth. These seem to play a great part in the formation of the language.

Another point which strikes one in looking through Sir Richard Temple's grammar of the language is the section dealing with the particles which he styles 'connectors of intimate relation.' These, it must be confessed, remain somewhat of a mystery; apparently they partake of the nature of prepositions, yet in their use they sometimes perform (it seems) the functions of what we should call the copula. I am not sure that Sir Richard Temple's account of them, which is necessarily involved with his analysis of the sentences in which they occur, can always be accepted as satisfactory. For instance, he says that one of the functions of the 'connector of intimate relation,' $t a$, is to connect the indicator (noun) with its explicator (adjective), and gives as an example, inter alia, the sentence inôat ta shong ôt, literally 'knife c.i.r. sharp is' = 'the knife is sharp,' which he analyses thus: inôat ta shong = subject, ôt (" is') = predicate. I should have thought that shong, 'sharp,' was an essential part of the predicate here; if not, surely the sentence would have to mean 'the sharp knife exists' or 'there is a sharp knife'? Similarly, in the sentence kenyum tai an ta fiñowa, literally 'child by he c.i.r. beat' = 'the child was beaten by him,' I should have thought that fiñowa was performing the function of a predicator (verb), not (as Sir Richard Temple considers) of an explicator. (adjective); if it were the latter, it seems to me that the words could only mean 'the child beaten by him.' However that may be, it is plain that this subject of ' connectors of intimate relation' calls for more detailed investigation, and I venture to think that a careful and comprehensive analysis of the uses of these particles will 
throw a flood of light on the inner syntactical structure of the language. In this respect they remind me of the so-called 'ligations' of the Malayo-Polynesian languages, the real nature of which was for a long time an absolute mystery, and is in fact still in course of being elucidated by patient comparative study.

I cannot here even allude to the other sections of the Nicobarese grammar; both in it and in the Andamanese there is a large amount of valuable matter, systematically arranged and clearly set forth. It whets one's appetite for more, for it must be borne in mind that only one out of the twelve forms of Andamanese and only one out of the six dialects of Nicobarese have as yet been at all adequately studied and made available as material for further studies. ${ }^{1}$ In view of the fact that these two languages occupy such a singularly important place and are of such special interest from the purely linguistic point of view (for, of course, as practical media of intercourse or as vehicles of literature they do not count), does not the further and more comprehensive study of them present itself as one of the most immediate desiderata of linguistic science? The urgency of the case is accentuated by the fact that the populations which speak them are not only falling more and more under foreign influence, but actually dwindling in numbers and probably dying out, so that these languages are in danger of becoming extinct. I venture to commend their cause to the Linguistic Survey of India (if it has not already extended its sphere of operations so as to include them) as being eminently deserving of its prompt attention.

\section{O. Blagden.}

1 When writing this I had for the moment forgotten Portman's and de Roepstorff's works on some of the other Andamanese and Nicobarese languages respectively. But even allowing for these, much still remains to be done. 